\title{
A Literature Review on Human Changeover Ability in High-variety Production
}

\author{
Christopher Ketelsen $(\bowtie)^{[0000-0003-1735-4617]}$, Rasmus Andersen ${ }^{[0000-0001-6788-8217]}$, Kjeld \\ Nielsen ${ }^{[0000-0002-3720-167 X]}$, Ann-Louise Andersen ${ }^{[0000-0002-7923-6301]}$, Thomas D \\ Brunoe ${ }^{[0000-0002-9847-6562]}$, Sofie Bech \\ Department of Materials and Production, Aalborg University, Denmark \\ christopherketelsen@gmail.com
}

\begin{abstract}
The business strategy of Mass Customization, enabled by e.g. Reconfigurable Manufacturing and Changeable Manufacturing is based on the fundamental premise; to achieve high operational efficiency, while producing high-variety products in small batches and with short product-life cycle of the unique products. To efficiently achieve this premise in manufacturing systems, all levels of changeability must be addressed. This paper investigates a fundamental sub-set of this changeability, which has not been addressed comprehensively by academia; the human changeover ability on workstation level. Based on a literature review, this paper identifies seven human related challenges which must be addressed to be able to manage high-variety and lowvolume efficiently on a changeover ability level. This leads to a subsequent literature review that aims at investigating possible approaches and solutions for the identified challenges. Overall seven approaches and solutions have been identified which address five of the seven identified challenges. This leaves two challenges open; the forgetting and learning curve. These two challenges are therefore proposed for further research to be at the cutting edge of an emerging challenge organizations striving for high-variety production will meet.
\end{abstract}

Keywords: Changeover Ability, Human Changeover Ability, Changeability, Changeable Manufacturing, Mass Customization

\section{$1 \quad$ Introduction}

High-variety production, often related to the business strategy of Mass Customization has experienced increased attention throughout the last decade both in academia [1], as well as in the industry [2]. The requirement to produce a higher variety of products, accompanied by decreasing production volume relative to both the batch-sizes in production as well the overall product-life-cycle (PLC) of products, causes challenges for traditional dedicated manufacturing systems [3]. To cope with these conditions, changeability has to be developed on all structural levels spanning from the supplychains agility to the workstations changeover ability [4]. Arguably, changeability has to be developed bottom-up, with the changeover ability being the fundament for all other changeability-levels [5]. Changeover ability is hereby defined as "[...] the operative ability of a single machine or work-station to perform particular operations 
on a known work piece or subassembly at any desired moment with minimal effort and delay. "[4]. Addressing changeover ability on the workstation level therefore becomes crucial in order to strengthen a factory's changeability [6]. Achieving changeover ability requires both physical, logical and human enablers [7]. Physical changeover ability relates to the machines and equipment, whereas the logical changeover ability relates to the planning and scheduling of the system components. Human changeover ability relates to the human, and more specifically the operator on the workstation level. Focus for the human changeover ability is the operators' ability to cope with a large variety of tasks both cognitively as well as skill wise. All of the three enablers have to be addressed in order to achieve comprehensive changeability [8]. While physical changeability enablers have been widely addressed in research on lower structuring levels of the factory including the workstation [9], focus on addressing the human enabler remains limited. To investigate this gap in literature, this review has the purpose to address the requirements that must be fulfilled to achieve human changeover ability. Subsequently, existing literature addressing these requirements will be reviewed to investigate the current state-of-art. This will lead to an assessment and documentation of gaps between the investigated requirements and the methods presented in existing literature, which will suggest viable new research directions. The research questions for this paper are:

RQ1: Which requirements does high variety production impede for the human changeover ability?

RQ2: Which solutions exist to address challenges on human changeover ability?

$R Q 3:$ Which gaps between literature and requirements are required to be closed?

\section{Requirements for Human Changeover Ability in High-variety Production}

This section presents challenges that must be addressed to achieve human changeover ability in high-variety production environments. Focus in this article will be on the human changeover ability in traditional factories, which still constitute the majority of industry [10]. The following section will be built around the challenges caused by the increased variety and the accompanied reduced volume respectively. The challenges within each field have been identified by reviewing literature, which often indirectly address the implied challenges caused by them.

\subsection{Requirements Caused by Increased Product Variety}

Increasing the variety of products offered by a company affects the manufacturing systems significantly, as variety proliferates on all levels and creates new requirements for processes and the workstations that perform these processes [11]. Intuitively, the increased amount of product varieties increases the amount of unique production configurations in the manufacturing systems. For operators, this increases the number of different configurations that must be operated [12]. It therefore requires broader skillsets of the operators to operate the manufacturing system. As a further consequence 
of the increased variety, time between operating the same configuration increase, which challenges the operator in recalling the specifics of each configuration. This phenomenon is referred to as the forgetting curve and is related to increased re-work and decreased efficiency as a function of increased time and other tasks in between performing the same configuration [13]. Another challenge for the human changeover ability, is the increased automation as an enabler for the production systems changeability[4]. Automation thereby in general has the purpose to automate simple and routine operations currently performed by operators. This increases the density of the complex and undefinable operations left for the operators, resulting in overall more complex work tasks for the operator [13]. Finally, with the increased automation, the interaction between operator and machines will become of increased importance. This requires the operators acquire skills to interact with the interface of the machines and furthermore be adaptable and flexible to resolve problems with the machines [6].

\subsection{Requirements Caused by Decreased Volume}

Apart from the requirements related to the increased variety, the reduced production volumes also affect the operators' changeover ability. This holds true for both day-today operations, as well as for the whole PLC. By reducing the production batch volumes in day-to-day operations, the number of changeovers performed relative to the overall production quantities are increased. Apart from reducing the overall efficiency of the manufacturing system, this also increases the workload of the operators, if performed manually. It is therefore required to find an efficient solution to decrease the changeover times to achieve the desired number of changeovers with the available resources. Relative to the reduced volume and implicitly length of the PLC connected to the mass customization paradigm, the learning curve of operators relative to new production configurations gets challenged [16]. To operate and changeover to a new production configuration efficiently, several repetitions and sufficient operation time are required [17]. By reducing the PLC of the unique production configurations, the amount of repetitions and operation time get decreased corresponding. This thereby increases the amount of comparably inefficient production time of a product on the learning curve relative to the fully efficient production time [18]. This emphasizes the requirement for faster learning of new production configurations to achieve satisfactory production efficiency for the overall PLC. The decreased PLC further challenges the current approach to continuous improvement $(\mathrm{CI})$ initiatives. In a simplified version, CI initiatives are based on historical learnings, which are converted into new procedures to improve processes and increase efficiency. Reducing the PLC, will correspondingly reduce the time where learnings can be converted into improvements, within the lifetime of a production configuration. 


\section{Solutions for Human Changeover Ability in High-variety Production}

Based on the challenges identified in the previous section, this section introduces how these are addressed by research with the purpose to identify shortcomings and gaps in relation to achieving changeover ability in the context of high-variety production. The findings are summarized in Table 1.

\subsection{Solutions for Variety Related Challenges}

Four different approaches have been identified in literature to address three out of the four variety related challenges. The first presented approach is competence training, focusing on increasing the competencies of the operators [19-21]. By training, a deeper understanding of the required competence is gained, instead of memorizing the skill in focus. Even though not reducing the workload, this approach thereby increases the holistic insight and interpretation of various tasks thereby enabling intuitive operation of a larger variety of tasks. This approach can be applied to three different challenges, respectively to broaden the operators' skillset, optimize the execution of complex tasks or to equip the operator with competencies for the interaction with the machines of the manufacturing system. By upskilling operators, their work motivation and morale gets increased, while simultaneously dependency of the specific human likewise is increased for the organizations point of view [15]. Another approach to address the mentioned challenges is by introducing information systems based on augmented technology to assist the operator $[12,19]$. Instead of storing the complexity and required knowledge at the operator, it can be stored and communicated by the information system. This decreases the dependency of the specific operator, but likewise also the motivation and knowledge. Apart from the knowledge-based approaches, two organizational approaches must be foretaken to address the density of complex tasks. To handle the increased complexity, the operators are required to have corresponding autonomy and empowerment $[4,12,22]$. This requires the operators both to take responsibility for demanding decisions and furthermore get allocated the corresponding authority to do so. To support the described autonomy, a flat organization is required to enable the operators to rapidly take complex decisions $[4,12]$.

\subsection{Solutions for Volume Related Challenges}

There have been identified three approaches to address two out of the three presented volume related challenges. First, the Single minute of exchange (SMED) methodology can be applied to optimize changeover procedures and processes and reduce the duration of the single changeovers to free capacity for the increased amount [16]. Yet, this approach concerns retrospective improvement. To achieve proactive improvements of the changeovers, the design-for-changeover approach can be applied in design of products or processes [16]. In order to address the decreased CI effect relative to the PLC, compressed kaizen events in the early phases of the PLC can be suggested [23]. This initiative enables to rapidly improve the new production configurations and 
correspondingly reap the benefits in the subsequent PLC. Yet, this approach requires high amount of commitment and resources of the organization for each production configuration, which may, when considering reduced PLC's, result in negative economic impact.

\subsection{Research Gap}

Based on the literature review summarized in table 1, two of the seven challenges are not addressed sufficiently in literature, respectively the learning and forgetting curve. Even though both concepts are addressed in their respective subject area, and furthermore on a general operations management level, their impact on increasing product variety and decreased production volume are not addressed and solutions are not found. It is therefore required to investigate the effect of both the learning and forgetting curve

Table 1. List of approaches addressing the presented challenges

\begin{tabular}{|l|c|l|c|l|l|l|l|}
\cline { 2 - 7 } \multicolumn{2}{c|}{ Challenge } & \multicolumn{5}{c|}{ Variety related challenges } & \multicolumn{3}{c|}{ Volume related challenges } \\
\hline Approach & $\begin{array}{l}\text { Broader } \\
\text { skillset }\end{array}$ & $\begin{array}{l}\text { Forgettin } \\
\text { g curve }\end{array}$ & $\begin{array}{l}\text { Density } \\
\text { of } \\
\text { complex } \\
\text { tasks }\end{array}$ & $\begin{array}{l}\text { Human/ } \\
\text { machine }\end{array}$ & $\begin{array}{l}\text { Increase } \\
\mathrm{d} \\
\text { changeo } \\
\text { vers }\end{array}$ & $\begin{array}{l}\text { Decrease } \\
\mathrm{d} \\
\text { learning } \\
\text { curve }\end{array}$ & $\begin{array}{l}\text { Decrease } \\
\mathrm{d} \\
\text { effect }\end{array}$ \\
\hline Competence Training & $\mathbf{X}$ & & $\mathbf{X}$ & $\mathbf{X}$ & & & \\
\hline Augmented technology & $\mathbf{X}$ & & $\mathbf{X}$ & $\mathbf{X}$ & & & \\
\hline Autonomy & & & $\mathbf{X}$ & & & & \\
\hline Flat organization & & & $\mathbf{X}$ & & & & \\
\hline SMED & & & & & $\mathbf{X}$ & & \\
\hline Design for change-over & & & & & $\mathbf{X}$ & & $\mathbf{X}$ \\
\hline Kaizen events & & & & & & & \\
\hline
\end{tabular}

on the changeover ability of the human operators in high-variety production environments. Without further research on the presented challenges, companies striving for increased product variety and decreased production volume will be able to achieve changeover ability on both the physical and logical yet lack the human aspect. With one enabler lacking, this will hinder the company's changeability and result in inefficient business processes, undermining the overall objective.

To address the presented challenges, research directed towards digital assistance systems can be suggested. These systems must be designed to deliver the required information necessary for the operators for either faster learning or avoidance of forgetting in an easy understandable way. This requires joint effort in research between operations management, cognitive psychology and software-development. Inspiration can be drawn from research within the field of conducting assembly instructions, where major overlaps relative to investigated challenges and solutions are present[24].

\section{Conclusion}

Human enablers of changeability have been neglected by academia in the rise of production philosophies striving for higher production variance and lower production 
volumes. This paper has shed light on seven challenges related to human changeability and more specifically human changeover ability on workstation level. A literature review on the seven discovered challenges within several academic areas revealed approaches and solutions for five of the seven challenges, leaving two challenges unresolved; the forgetting curve and the learning curve. It can therefore be concluded that further research must be conducted which addresses these specific challenges in the light of human changeover ability in a production environment. Corresponding approaches and solutions must be devised to be at the cutting edge of an emerging challenge organizations striving for mass customization will meet.

\section{References}

1. Fogliatto, F.S., Da Silveira, G.J.C., Borenstein, D.: The mass customization decade: An updated review of the literature. Int J Prod Econ 138, 14-25 (2012).

2. Slamanig, M.: Einleitung. In: Produktwechsel als Problem im Konzept der Mass Customization, pp. 1-16, Gabler, Wiesbaden (2011).

3. Koren, Y., Shpitalni, M.: Design of reconfigurable manufacturing systems. J Manuf Syst 29, 130-141 (2011).

4. ElMaraghy, H.A., Wiendahl, H-P.: Changeability - An Introduction. In: ElMaraghy, H.A. (ed.) Changeable and Reconfigurable Manufacturing Systems, pp. 3-24. Springer London, London (2009).

5. Owen, G.W., Matthews, J., McIntosh, R.I., Culley, S.J.: Design for Changeover (DFC): Enabling Flexible and Highly Responsive Manufacturing. In: Fogliatto, F.S., da Silveira, G.J.C. (eds.) Mass Customization: Engineering and Managing Global Operations, pp. 247-273. Springer London, London (2011).

6. Wiendahl, H-P., ElMaraghy, H.A., Nyhuis, P., et al.: Changeable Manufacturing Classification, Design and Operation. CIRP Ann - Manuf Technol 56, 783-809 (2007).

7. Deif, A.M., ElMaraghy, W.H.: A Systematic Design Approach for Reconfigurable Manufacturing Systems. In: ElMaraghy, H.A., ElMaraghy, W.H. (eds.) Advances in Design, pp. 219-228. Springer London, London (2006).

8. Rösiö, C.: Supporting the Design of Reconfigurable Production Systems. Mälardalen University (2012).

9. Andersen, A-L., Brunoe, T.D., Nielsen, K.: Reconfigurable Manufacturing on Multiple Levels: Literature Review and Research Directions. In: Umeda, S., Nakano, M., Mizuyama, H., et al. (eds.) Advances in Production Management Systems: Innovative Production Management Towards Sustainable Growth, pp. 266-273. Springer International Publishing, Cham (2015).

10. Verzijl, D., Dervojeda, K., Jorn, S-K-F., et al.: Smart Factories Capacity optimisation, 17 (2014).

11. Elmaraghy, H., Schuh, G., Elmaraghy, W., et al.: Product variety management. CIRP Ann - Manuf Technol 62, 629-652 (2013).

12. Gehrke, L., Kühn, A.T., Rule, D., et al.: A Discussion of Qualifications and Skills in the Factory of the Future. Hann Messe 2015, 28 (2015).

13. Jaber, M.Y., Bonney, M.: Lot sizing with learning and forgetting in set-ups and in 
product quality. Int J Prod Econ 83, 95-111 (2003).

14. Wiendahl, H-P., Reichardt, J., Nyhuis, P.: Production Requirements. In: Handbook Factory Planning and Design, pp. 29-62. Springer Berlin Heidelberg, Berlin, Heidelberg (2015).

15. Waschull, S., Bokhorst, J.A.C., Wortmann, J.C.: Impact of Technology on Work: Technical Functionalities that Give Rise to New Job Designs in Industry 4.0. In: Lödding, H., Riedel, R., Thoben, K-D., et al. (eds.) Advances in Production Management Systems. The Path to Intelligent, Collaborative and Sustainable Manufacturing, pp. 274-281. Springer International Publishing, Cham (2017).

16. McIntosh, R., Owen, G., Culley, S., Mileham, T.: Changeover improvement: Reinterpreting Shingo's “SMED” methodology. IEEE Trans Eng Manag 54, 98-111 (2007).

17. Anzanello, M.J.: Selecting Relevant Clustering Variables in Mass Customization Scenarios Characterized by Workers' Learning. In: Fogliatto, F.S., da Silveira, G.J.C. (eds.) Mass Customization: Engineering and Managing Global Operations, pp. 291304. Springer London, London (2011).

18. Elmaraghy, W.H., Nada, O.A., Elmaraghy, H.A.: Quality prediction for reconfigurable manufacturing systems via human error modelling. Int J Comput Integr Manuf 21, 584 598 (2008).

19. Wiendahl, H-P.: Systematics of Changeability. In: Handbook Factory Planning and Design, pp. 91-118. Springer Berlin Heidelberg, Berlin, Heidelberg (2015).

20. Gerst, D.: Designing Workplaces from a Work Organizational Perspective by Detlef Gerst. In: Handbook Factory Planning and Design, pp. 169-195. Springer Berlin Heidelberg, Berlin, Heidelberg (2015).

21. Acatech Kompetenzentwicklungsstudie Industrie 4.0 (2016)

22. Lall, M., Torvatn, H., Seim, E.A.: Towards Industry 4.0: Increased Need for Situational Awareness on the Shop Floor. In: Lödding, H., Riedel, R., Thoben, K-D., et al. (eds.) Advances in Production Management Systems. The Path to Intelligent, Collaborative and Sustainable Manufacturing, pp. 322-329. Springer International Publishing, Cham (2017).

23. Farris, J.A., Van Aken, E.M., Doolen, T.L., Worley, J.: Critical success factors for human resource outcomes in Kaizen events: An empirical study. Int J Prod Econ 117, 42-65 (2009).

24. Claeys, A., Hoedt, S., Van Landeghem, H., Cottyn, J.: Generic Model for Managing Context-Aware Assembly Instructions. IFAC-PapersOnLine 49, 1181-1186 (2016). 